\title{
A study of Zajonc's theory of social facilitation using a wheel-turn Sidman avoidance response in rats
}

\author{
JAMES O. BENEDICT \\ James Madison University, Harrisonburg, Virginia 22807 \\ JOHN L. COFER \\ Emory and Henry College, Emory, Virginia 24327 \\ and \\ MICHAEL W. COLE \\ James Madison University, Harrisonburg, Virginia 22807
}

\begin{abstract}
Rat subjects were used to study the acquisition of a wheel-turn Sidman avoidance response under three levels of social interaction: physical, spectator, and single subjects. Zajonc's (1965) theory of the effects of social interaction was supported. Subjects run alone acquired the avoidance response quickly, but subjects run with spectators or with co-responders did not acquire the response.
\end{abstract}

Previous studies have shown that the presence of an audience had either a facilitative or an inhibitive effect on a subject's behavior (Ader \& Tatum, 1963; Davitz \& Mason, 1955). Zajonc (1965), in a review of the literature, attempted to clarify the apparently conflicting results. He theorized that social interaction both impaired the learning of a new response and facilitated the performance of a previously well-learned behavior.

Zentell and Levine (1972) found that rats were impaired in their acquisition of a barpress response for water when a physically separated audience was present. Cunningham and Roberts (1973), using a Sidman avoidance paradigm, found that rats trained alone acquired a barpress response more readily than those trained in pairs. Both of these results supported Zajonc's (1965) theory of social facilitation; however, Cunningham and Roberts' study was designed in a biased fashion to favor Zajonc's theory. First, they chose a response that has been found to be difficult for rats to learn in avoidance situations (Bolles \& McGillis, 1968; Meyer, Cho, \& Wesemann, 1960), and second, in their paired group, subjects could physically interact while getting shocked. Placing subjects together in the same chamber while they are shocked has been shown to produce disruptive aggressive behavior (cf. Azrin, Hutchinson, \& Hake, 1967). This physical interaction

Requests for reprints should be sent to James O. Benedict at the Department of Psychology, James Madison University, Harrisonburg, Virginia 22807. M. W. Cole is now at the Southside Virginia Training Center for the Mentally Retarded in Petersburg, Virginia. J. L. Cofer is now at the University of Tennessee. may have amplified the learning impairment during the acquisition of the avoidance response.

The following experiment studied the effects of three levels of social interaction on the acquisition of a Sidman avoidance response. The physical level paradigm offered the highest level of interaction, in which subjects were paired and capable of coming into physical contact. This level replicated the social interaction condition run by Cunningham and Roberts (1973). The intermediate level involved a spectator paradigm and had not been employed by Cunningham and Roberts (1973). Here physical contact was prevented by placing a wire-screen divider between the subject learning the avoidance response and a naive audience which was yoked with shock to the avoider. This level controlled for the possible interference effect of physical contact while allowing maximum interaction of other social cues (e.g., olfactory and visual). In the lowest, or zero, level of interaction, the subjects were run alone with the wire-screen divider present. This level tested the effects of learning without an audience and controlled for any effects produced by the apparatus or divider.

The avoidance response chosen was the rotation of a small wheel. Weiss (1971) and others have found that the use of this response led to high response rates and was fairly easy for the rat to learn.

It was predicted that the subjects trained alone would learn the behavior faster than the other two audience levels. It was also expected that with the removal of any physical interference by the audience, the spectator paradigm might show better acquisition than the physical paradigm. 


\section{METHOD}

\section{Subjects}

Eighteen female Sprague-Dawley rats purchased from Flow Laboratories, Dublin, Virginia, were assigned to individual cages and handled often before the beginning of the experiment. Subjects were experimentally naive and between 98 and 105 days old at the start of experimentation. Food and water were given ad lib, except when the subjects were in the operant chamber, where neither was available.

\section{Apparatus}

Three BRS-Foringer dual-ever operant chambers (Model 14322) were modified by removing the food tray, the three cue lights, and both response levers.

The manipulandum, a $7.3 \times 6.4 \mathrm{~cm}$ (width by diameter) wheel, was placed on the left side of each chamber with its axis $7.6 \mathrm{~cm}$ above the grid floor. This wheel projected $1 \mathrm{~cm}$ from an opening in a $7.9 \times 10.2 \times 15.2 \mathrm{~cm}$ (length by width by height) aluminum box. Downward pressure on the wheel caused a microswitch closure with each revolution, but upward pressure did not turn the wheel. The inside of the aluminum box was lined with sound-attenuating material. A metal plate from the ceiling to the aluminum box prevented the subjects from climbing on top of the box. Styrofoam packing material behind this plate and a block of wood standing next to the plate and the wheel unit prevented unauthorized escape behind the plate.

A chamber divider partitioned the chamber into a right and a left compartment when subjects were run alone or when they needed to be separated. This divider was made of metal screen $(7.1 \times 6.3 / \mathrm{cm}$ mesh) sealed in a Plexiglas frame. When the divider was present, another metal plate was placed firmly on the right side of the chamber to hold it firmly against the block of wood seated next to the wheel unit and its top plate. This second plate also made the right side of the chamber approximately equal in size to the left. Styrofoam packing material was also placed behind the second plate to prevent unauthorized escape.

The entire modified operant chamber was housed in a ventilated sound-attenuated box. A BRS-Foringer shock generator (Model SG-901) and scrambler (Model SC-901) were programmed to deliver a $.2-\mathrm{sec} .8-\mathrm{mA}$ shock. Masking noise was continuously present during experimentation at a level of $80 \mathrm{~dB}$.

\section{Procedure}

The experiment employed three different social interaction paradigms: physical paradigm, spectator paradigm, and the single-subject paradigm. Each paradigm placed the subjects learning the avoidance response under differing degrees of social interaction. The highest level of interaction was available in the physical paradigm. Here, subjects were paired and capable of coming into physical contact. Both subjects had access to the manipulandum and could respond to avoid shock. The next level, the spectator paradigm, yoked paired subjects to shock and prevented physical contact by separating them with a wirescreen divider. The divider eliminated tactile cues while allowing the continued interaction of olfactory, visual, and auditory cues. Only the avoider had access to the manipulandum; the other subject (the spectator) provided the social influence. The single-subject paradigm provided for the lowest level of interaction. The procedure was identical to the spectator paradigm, except no audience was present.

The subjects were randomly assigned to groups with three avoiders in each and counterbalanced with respect to running order and test chamber. Each session last $1 \mathrm{~h}$ daily for each subject for a minimum of 20 days, using the Sidman avoidance schedule of a shock-shock interval of $5 \mathrm{sec}$ and a responseshock interval of $15 \mathrm{sec}$.

\section{RESULTS AND DISCUSSION}

Table 1 shows the average response and shock rates for each subject over the last 5 days of training, as well as the total number of training sessions each subject received. A response rate less than 240 responses signified 1 response after each response-shock interval. A total absence of responding resulted in 720 shocks/ session.

The results of the experiment show that those subjects in the single-subject group learned to respond to the Sidman avoidance schedule better than the groups paired with an audience. Their response rates were generally higher and their shock rates definitely lower than the other two social groups. These results replicated those of Cunningham and Roberts (1973) using Sidman avoidance and Zentall and Levine (1971) using appetitive drive. The spectator paradigm group, did not differ greatly from the physical paradigm group. One animal in each of the two social groups did acquire a response rate over 300 responses/h, but the spectator paradigm's good responder was more effective because it received about half of the shocks that the physical paradigm's good responder received. The other two members of the physical paradigm group showed a nearly complete lack of responding; the other two members of the spectator paradigm group showed a marginal level of responding.

It could be concluded from these data that, when the possibility of audience physical interference is eliminated, Zajonc's (1965) theory is still supported in that social interaction impairs the acquisition of a new behavior.

One possible confounding variable that was not controlled was the specified shock intensity received by the rats in the two paired conditions. When two rats were placed on the same grid floor, the experienced

Table 1

Number of Sessions and Mean Response and Shock Rates of Each Subject per Session Over the Last Five Sessions of Training in Experiment 1

\begin{tabular}{lccl}
\hline Condition & Sessions & Responses & Shocks \\
\hline PP1 & 33 & 346.9 & 352.0 \\
PP2 & 15 & .5 & 698.4 \\
PP3 & 15 & .8 & 704.4 \\
Mean & & 116.1 & 584.9 \\
SP1 & 20 & 27.0 & 488.4 \\
SP2 & 23 & 339.3 & 149.4 \\
SP3 & 20 & 21.4 & 542.6 \\
Mean & & 129.2 & 393.5 \\
& & & \\
SS1 & 26 & 364.0 & 50.2 \\
SS2 & 21 & 556.8 & 29.0 \\
SS3 & 20 & 1316.7 & 49.4 \\
Mean & & 745.9 & 42.9 \\
\hline
\end{tabular}


intensity for each rat was somewhat less than $.8 \mathrm{~mA}$. In fact, with our equipment it ranged from approximately $.5 \mathrm{~mA}$ to $.6 \mathrm{~mA}$. It is possible that the rats in these groups did not learn the avoidance response because of the reduced shock intensity. However, researchers have shown (e.g., Bolles \& Warren, 1965) that rats can learn a barpress avoidance response with a shock as low as $.4 \mathrm{~mA}$. However, this may be a controlling variable and should be studied in future social interaction avoidance experiments.

\section{REFERENCES}

Ader, R., \& TAtum, R. Free operant avoidance in individual and paired human subjects. Journal of the Experimental Analysis of Behavior, 1963, 6, 357-359.

Azrin, N. H., Hutchinson, R. R., \& Hake, D. F. Attack, avoidance and escape reactions to aversive shock. Journal of the Experimental Analysis of Behavior, 1967, 10, 131-148.

Bolles, R. C., \& McGillis, D. B. The non-operant nature of the bar press escape response. Psychonomic Science, 1968, 11, 261-262.

Bolles, R. C., \& Warren, J. A. The acquisition of bar-press avoidance as a function of shock intensity. Psychonomic Science, 1965, 3, 297-298.

Cunningham, W. L., \& Roberts, A. E. Acquisition and maintenance of Sidman avoidance with paired subjects. Animal Learning \& Behavior, 1973, 1, 44-48.

DAvitz, J. R., \& MASON, D. J. Socially facilitated reduction of a fear response in rats. Journal of Comparative and Physiological Psychology, 1955, 48, 149-151.

Meyer, D. R., Cho, C., \& Wesemann, A. F. On problems of conditioning discriminated lever-press avoidance responses. Psychological Review, 1960, 14, 327-334.

WEISS, J. M. Effects of coping behavior in different warning signal conditions on stress pathology in rats. Journal of Comparative and Physiological Psychology, 1971, 77, 1-13.

ZaJONC, R. B. Social facilitation. Science, 1965, 149, 269-274.

Zentall, T. R., \& Levine, J. M. Observational learning and social facilitation in the rat. Science, 1972, 178, 1220-1221.

(Received for publication January 8, 1980.) 